\title{
English Language Development in JAIST Japan
}

\author{
Zuraidah Zaaba ${ }^{1}$, Takashi Hashimoto ${ }^{2}$, MaryAnn Mooradian², Haijon Gunggut ${ }^{1}$ \\ UiTM Malaysia Sabah Branch ${ }^{1}$, JAIST Japan ${ }^{2}$
}

\begin{abstract}
Japan is a country in which the mother tongue is sacred. However, globalization has made English language increasingly important in Japanese higher education institutions. In support of globalization, the Japan Ministry of Education has introduced "Global 30" and Gendai Programs. Henceforth, there is development of English language in Japanese higher education institutions. As our preliminary research, we analyze the approach taken by Japan Advanced Institute of Science and Technology (JAIST) to develop an English language program. We choose JAIST because they are the leader for internationalizing an educational program in advanced science and technology in Japan particularly for postgraduate studies. The findings show that JAIST leaders first emphasize contribution to the advancement of world science, in accordance with rapid internationalization since the 1990s. The contribution is the continuous development of English programs for science and technology. Second, they cultivate potential scientists by acceptance of foreigners as students, postgraduates and faculty members; collaboration with visiting researchers; agreements on academic exchanges with foreign universities and institutes; and holding international symposia. These steps further create an internationalized environment in JAIST. These two approaches lead to the continuous development of English language programs in JAIST. Hence, there is integration of Japan's science and technology in internationalization.
\end{abstract}

\section{Introduction}

Japan, being a developed nation before World War II (WWII) [12], took multiple steps to recover from the devastation of the War. One step was to make Japan one of the industrial states again. The government of Japan in the late 1940s and early 1950s initiated a strategy which consisted of four elements:

- Concentration on technical information acquisition and management;

- Directed investment in academic research based on selected national goals;

- Government participation in selected industrial initiatives;

- Heavy investment in education at every level.
The Japanese government established the Japan Institute of Science and Technology (JIST). JIST procured the first computers in Japan. They sent bibliographic experts to the west to learn about information storage systems, and then offered services to Japanese business and industry. JIST was able to develop an extremely efficient and effective translation system [12][15]. This system allowed Japanese higher education institutions to continue using Japanese as a medium of instruction.

However, globalization has made English language increasingly important in Japanese higher education institutions. For Japan to be able to continue to be part of the knowledge industry, it needs to emulate what European countries are doing to attract foreign students to enroll in their higher education institutions (HEIs). The European HEIs are teaching science and technology courses in English [14].

Since the 1990s, English language has become increasingly important in Japanese HEIs; this coincided with the increase of foreign student enrollment in Japanese HEIs [3].The introduction of English programs in the HEIs serves as a method to enable Japan to be part of the knowledge industry.

\section{English Language in Japanese HEIs}

Recently, language planning as a whole in Japan has been responsive to politics (both domestic and overseas) and to demands for Japan to become an information society [10]. The government's commitment to a policy of internationalization requires continuation of the teaching of Japanese as a foreign language both inside and outside Japan, and improved teaching of English language in Japanese schools.

In the 1990s, Japanese HEIs began to increase foreign student enrollment. English language became increasingly important in the HEIs, mainly as a special service for overseas students [3]. Both public and private HEIs have introduced international programs in English for foreign and Japanese post graduates. The International Student Exchange Program (ISEP) offers short courses of one year or less to foreign students; and the University Mobility in Asia and the Pacific Program (UMAP) in Japan began in 2000, also bringing foreign students to Japan.

In addition, "Global 30" project was developed for establishing core HEIs for internationalization in 
Japan. This project allows top HEIs in Japan to offer a range of degree courses in a number of fields with English as a medium of instruction [5].

These top HEIs function as core education institutions for receiving and educating international students. This project attempts to break the language barrier which is one of the obstacles preventing international students from studying in Japanese HEIs [5].

In 2009, there were 13 HEIs selected as core HEIs for 'Global 30'centers. The 13 HEIs were:

- Sendai : Tohoku University

- Tsukuba : Tsukuba University

- Tokyo : The University of Tokyo

Keio University

Sophia University

Meiji University

Waseda University

- Nagoya : Nagoya University

- Osaka : Osaka University

- Kyoto : Kyoto University

Doshisha University

Ritsumeikan University

- Fukuoka : Kyushu University

These selected HEIs objective is 'to nurture internationally competent individuals by creating an academic environment where international students and Japanese students can learn from one another and building a long lasting international bonds that will propel them into international scene' [5].

Therefore, it is interesting to do research on English language development at one of the HEIs in Japan. This research explores how Japan HEIs implemented this objective. The Global Communication Center (GCC) (previously the Technical Communication (TC) Center) of Japan Advanced Institute of Science and Technology (JAIST) is an interesting case study, since JAIST is a higher education institution that has explicitly developed the English language program to fulfill their mission, which is to produce world-class researchers and engineers [8].

JAIST is not included as one of the core HEIs as it is a postgraduate institution. However, JAIST is given support by Ministry of Education, Culture, Sports, Science, and Technology Japan (MEXT) to emulate this 'Global 30' approach and develop in accordance with JAIST's mission and vision.

\section{Objectives}

The objectives of our research are:

- To analyze the development of the English language usage program in the GCC at JAIST.

- To identify the catalyst of English language usage in JAIST

\section{Methodology}

GCC in JAIST Japan is selected as the case study because it is a center that provides English language programs and services to all JAIST members.

Data was collected through interviews of JAIST staff (fieldwork was conducted in May and November 2010); and secondary data from the JAIST prospectus (1990-2010) and GCC. Interviews were conducted with the GCC teaching staff and JAIST faculty members and staff who were involved in the setting up of the center and provision of English programs in JAIST.

Data is analyzed from the knowledge management perspective, with emphasis on the Socialization, Externalization, Combination and Internalization (SECI) model [6].

\section{Knowledge management}

Knowledge management in the organization focuses on knowledge sharing, knowledge acquisition and knowledge utilization [1][2]. Knowledge sharing is disseminating and allowing easy access to knowledge for all groups and individuals in the organization. Paper or poster presentations and networking during conferences, formal or informal meetings for planning, decision making, evaluating or setting goals, and media announcements via radio, television or internet, are all examples of venues where knowledge can be shared.

Knowledge acquisition means developing and creating intellectual capital, which includes internal and external knowledge. For internal, the examples are insights, experience and relationships. As for external, the examples are the success and failure of other organizations and collaboration.

Knowledge utilization means that sharing and acquisition of knowledge are being utilized for the purposes of innovation, design and invention. This enables knowledge to be created internally and externally. Internally, organizations own knowledge as a result of formal and informal activities: some instances are research and development, and social gatherings, respectively. Externally, knowledge is based on other organizations' innovations, designs and inventions.

Knowledge sharing, knowledge acquisition and knowledge utilization will result in knowledge creation (see Figure 1). 


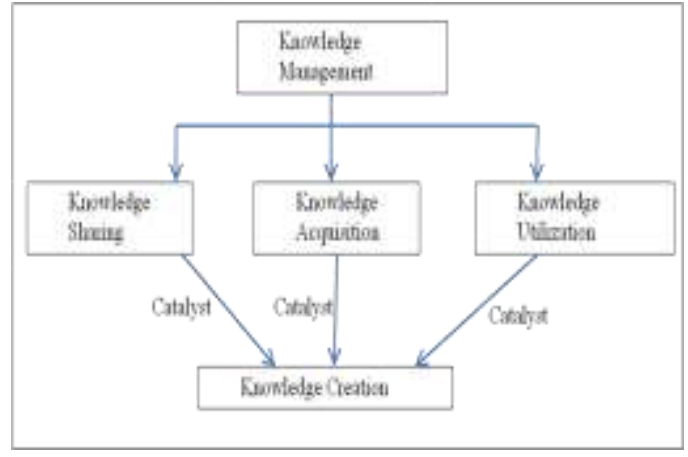

Figure 1. Management of knowledge [17]

SECI model (Figure 2.) is one basic model popularized by Nonaka and Takeuchi [6] of knowledge sharing, knowledge acquisition and knowledge utilization that lead to knowledge creation. Socialization means there is a process of sharing. Externalization means there is a process of creation. Combination means there is a process of utilization, and internalization means there is a process of acquisition.

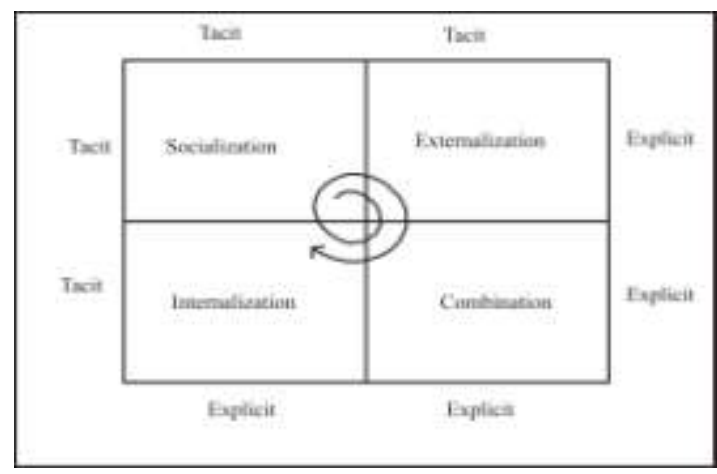

Figure 2. SECI model [17]

\section{Analysis and discussion}

\subsection{Japan Advanced Institute of Science and Technology (JAIST) Japan}

Japan Advanced Institute of Science and Technology (JAIST) Japan was founded on October 1, 1990. JAIST is the first independent national university to carry out graduate education based on the results of research at the highest level for the advancement of the frontiers of science and technology [8]. The original purpose of JAIST (in 1990) was to carry out basic research in the fields of information technology and new materials, and cultivate potential researchers and enterprising engineers with broad basic knowledge of their fields [8].

The fundamental principle of the founding of this institute is to create an "intelligent campus", a sophisticated atmosphere for advanced research and study of science and technology. The goals are codified in the "FRONT", which indicates "flexible, regional relations, open campus/network, nature and high tech". The first English language course "English composition and conversation" was offered to both the Materials Science and Information Science schools.

In the 1990s, JAIST began to emphasize its main aim, to contribute to the advancement of world science in accordance with the rapid internationalization of the 1990s. In response to the increasing importance of international exchanges and cooperation in study and research in the fields of advanced science and technology, JAIST seeks to cultivate potential scientists by accepting students from abroad, collaborating with visiting researchers and holding international symposia. In the 1990s, JAIST had concluded agreements on academic exchanges with several foreign institutes [8]. These are examples of foreign HEIs that collaborate with JAIST [9]:

Asia

- University of Technology MARA, Malaysia

- Hanoi University of Science, Vietnam

- University of Dhaka, Bangladesh

- $\quad$ Nanjing University, China

- University of Delhi, India

North, South and Central America

- University of California, Davis, USA

- Carleton University, Canada

- The University of Chile, Chile

\section{Europe}

- University of Innsbruck, Austria

- Czech Technical University, Czech

- University of Oulu, Finland

- Ecole Nationale Superieure d'Arts et Metiers, France

- The University of Hull, UK

Ocean

- Queensland University of Technology, Australia

Middle East

- Qatar University, Qatar

\subsection{The catalyst of English language development in JAIST Japan}

There are knowledge sharing and knowledge acquisition activities that require English language as a medium of communication. These were explicitly addressed through the JAIST leaders' vision and 
mission. These were emphasized in messages and strategic plans. In the year 2000, JAIST's second president, Etsujiro Shimemura, in his message, emphasized that there are no restrictions on recruiting faculty members and admitting students based on nationality or language [8]. In April, 2004, JAIST was incorporated as National University Corporation Japan Advanced Institute of Science and Technology [7]. The third president, Sukekatsu Ushioda, elaborated with the foreigners present; JAIST had become a cosmopolitan campus in which English is used as a second language [8].

The current president, Takuya Katayama, in his first message [8] ( interviewed on May 10 $0^{\text {th }} 2010$ ) reaffirmed president Sukekatsu Ushioda's assurance concerning English language, by highlighting the increasing importance of English language, because with 20 percent of students from foreign countries, JAIST is the most international among Japanese HEIs in the science and technology areas. The increase of foreign students is due to doctoral courses being taught in English language, and every important communication from the administration is in both English and Japanese.

\subsection{English services and program in GCC, JAIST}

As a result, in 2005, JAIST created an English Technical Communication (TC) program. TC offered students and faculty of JAIST a full range of coursework and advice to support their efforts to publish internationally in respected journals, and to become full members of the international community of scholars [8]. In 2009 TC became the Global Communication Center (GCC).

A wide variety of classes in English at all ability levels for specialists in science and technology, are provided for students in JAIST. They range from self-learning in the ubiquitous Language Laboratory (LL) environment and interaction seminars to specialized courses for conference presentations in English and tutoring services for conference presentations in English, specialized courses for research publications, and editing advice and assistance for research publications.

The students can study on their own using the LL system on campus to improve their skills. As for specialized courses for conference presentations in English language, students and staff can learn effectively either by attending the specialized course during the term, or in a one-week intensive course on presentations. Video feedback is provided for participants to improve their skills of presentation.

There is also a specialized course for research publications, and editing advice and assistance for research publications. The Center provides necessary advice for writing convincing essays and accurate journal articles in English. Students and faculty members are encouraged to either enroll in specialized courses during the term, or to take an intensive course. After attending the course, students use the services which assist them to publish and present their research internationally. "Communication in integrated and interdisciplinary fields" allows students in this program to learn the variety of communication skills required for research and technical development in integrated and interdisciplinary fields, to enable them to work in newly developed research areas and related industries.

Through lectures, writing practice, and discussion among students and researchers/academics in various areas, participants acquire the ability to explain their research to people outside their field, and to understand research in other fields. These classes teach participants to evaluate their skills, understand other people's comments and ideas, and develop a global perspective. Participants also practice making business plans in groups, in order to improve their interpersonal skills and project management abilities, based on seamless integration of fundamental research and applied research [8].

In 2008, GCC courses also included an intellectual course for students on "Critical Thinking and Scientific Discussion". This course also expanded, to include exploring the "Philosophy of Critical Thinking and Scientific Discussion", and a new course was created on "English for Mathematics and Etymology of Scientific and Technical Terms".

GCC enables JAIST researchers and engineers (students and academics) to take active roles in the global scientific and business communities. The center provides training in languages such as English and Japanese, as well as in communication skills useful in a wide range of areas, such as integrated and interdisciplinary fields and industries [8]. In 2009 GCC was placed along with other centers, offices and schools [8], and in 2010, GCC was placed directly under the Trustee and Vice President, Education Division [8]. The GCC's goals, mission and its programs and services for English language are the continuation of the TC goals and mission statement i.e. to support the internationalization of JAIST

\subsection{Knowledge creation in JAIST}

The English development in JAIST during the 1990s only evolved within the content of the English program and the use of technological aids in English class to advance the finding of information on the internet. Both Materials Science (MS) School and Information Science (IS) School in the early 1990s set up (externalize/create) a common course "English class for composition and conversation". The class was set up (externalize /create) as an intensive class, but when Miss Mooradian an English native speaker was employed, she saw the importance of enhancing 
the existing class to provide the necessary language skills. This advanced class enabled master and doctorate students to write and present their research findings (externalization/creation) at the international level. Hence, English language class in JAIST was developed (externalized /created) to serve its mission to become an international center of learning in the field of science and technology.

In 1996, Knowledge Science (KS) School was established with Master program, and later in 2000 doctorate program was established. From 1996 onwards the English language program began to develop rapidly. President Shimemura appointed an English native speaker, Dr. DiGiovanni, who has a $\mathrm{PhD}$ in technical communication. He also extended the use of English language via office emails. This allowed information in JAIST to be received and retrieved in both languages i.e. Japanese and English. This coincided with the increase of foreign students in JAIST.

During Dr. DiGiovanni's tenure, he developed (externalized/created) a program i.e. Technical Communication (TC) program that enhanced students' capability in speaking and writing in English. This program was for the three schools. However, this program was especially for KS school, because KS research areas are multidisciplinary i.e. integrating science and technology with nonscientific disciplines.

He began expanding (externalizing/creating) the English program comprised of courses from Basic English class to advanced class, tutorial class to support formal courses, conversation club and services for editing and presentation of research. He increased the number of part-time teaching staff. The English teaching staff were of different nationalities. This allowed multiple approaches to be developed (externalized/created) in the English Technical Communication (TC) program.

The expansion of English programs required additional budget. It was fortunate in 2005 that a new educational program 'Gendai Program' (GP), a Contemporary Education Needs Support Project was launched. This research was supported by the Japan Society for the Promotion of Science (JSPS) Grantin-Aid for Scientific Research. The aid included Kakenhi from 2006 to 2007 and Kakenhi from 2009 to 2011[4]. This Gendai Program was introduced for graduate schools by MEXT. One of the educational program categories was for English learning. JAIST was awarded funding from the Gendai Program from 2005 to 2009.

During this Gendai program, the TC program opened classes especially for the preparation of Test of English for International Communication (TOEIC). TOEIC was developed by the Educational Testing Service (ETS), the world's largest nonprofit test development organization established in 1947. ETS undertakes the development of a range of tests under its mission of 'advancing quality and equity in education'. In 1979, TOEIC was launched in Japan. Today, this test is the world's universal measure of skills in English as a second language. TOEIC is accepted by nearly 120 countries worldwide, and it plays a key role in promoting communication in English language [13].

This grant supported the expanding of teaching classes, hiring faculty and office staff, continuing of the part timers' service and providing offices for TC. Unfortunately before the Gendai Program ended, in 2006, Dr. DiGiovanni, the head of the TC program retired, and Professor Honda who was in charge of the Gendai Program took his sabbatical in 2008.

There was a need to hire faculty members to ensure that the Gendai Program, especially learning English, was continuously implemented. Professor Makishima took over and later Professor Yoshida was in charge of the Gendai Program and TC program. However, it was necessary to employ English speaking faculty members with research background. A new faculty member was employed in 2007, Associate Professor Terrillon, a Canadian with working experience in foreign and Japanese research institutions and specialized in physics. With his academic qualifications and experience in research he developed (externalized/created) courses in English to achieve the objective of Gendai Program i.e. science research. Beginning in 2008, he created the courses, "Critical Thinking and Scientific Discussions" for credit; and non credit courses "Philosophy of Science and Critical Thinking" and "Mathematics and Etymology of Science and Technical Terms".

In 2009, 'Global 30' project was introduced by the Japanese government. This project had a big impact on JAIST as a newly established graduate institution, as compared to other HEIs in Japan. The current president, Professor Katayama, emphasized explicitly internationalization and globalization in JAIST. He conveyed this in his speech during the entrance ceremony for 2010 enrollment of master and doctorate students.

Actually, in response to 'Global 30' project, Global Communication Center (GCC) was established in JAIST. GCC is responsible for Japanese Language and English language programs. GCC is placed under 'Education Division'. GCC is more dynamic than TC. A new faculty member of the GCC, Professor Kawanishi, who has working experience in HEIs in the USA, is entrusted to manage the GCC while Associate Professor Terrillon is responsible for curriculum development.

Professor Kawanishi and GCC staff continued to create courses of English language and courses in English language. Henceforth, there are more workshops and well-planned non-credit courses in English language. He added variety to English courses at GCC. The initial courses were more about 
social, cultural and intercultural communication. In 2012, courses about Japan and international relations were added for both Japanese and foreign students, with the objective that they learn to be active internationally.

GCC increases courses using English as the language of instruction. The purpose is for students to explore multidisciplinary areas. The creation of knowledge is important for JAIST students to play active roles globally in science and technology. The courses also extend to JAIST staff. Eventually, all these courses will promote English language as one of the languages used in JAIST. This coincides with President Katayama's mission, the 'globalization' and 'internationalization' of JAIST.

There is collaboration with University of California Davis (UC Davis) to send JAIST students to USA during the term break; and research collaboration with UC Davis and Ritsumeikan University to develop English programs specifically for graduate students.

The Japanese language program also will be developed for foreign students in and outside of JAIST. This indirectly will increase foreign students, and increase the use of English language in JAIST. The reorganizing of GCC, Career Service Center and a new center for Liberal Arts or General Study under The School of Fundamental Arts will further strengthen English to be one of the languages used along with Japanese in JAIST.

\section{Conclusion}

The leaders (presidents) of JAIST are the catalyst for the development of English language programs in JAIST. First, since the 1990s, the leaders have emphasized the contribution of English to the advancement of world science, in accordance with rapid internationalization. Second, they cultivate potential scientists by the acceptance of foreigners as students, postgraduates and faculty members; collaboration with visiting researchers; agreements on academic exchanges with foreign universities and institutes; and holding international symposia.

Their actions have developed the English language program i.e. learning English language in general, and learning English language for science and technology. This is continuously expanding to achieve globalization /internationalization of science and technology. In 2012, GCC has now been integrated into the Institute of General Education, and renamed the Global Communication Education Department.

\section{Acknowledgements}

We would like to thank Professor Takuya Katayama, the President of Japan Advanced Institute of Science and Technology (JAIST) for sharing his vision of internationalization of JAIST. We also thank Professor Honda for his knowledge about English language development in JAIST. Finally, thank you to the academic and non-academic staff of Global Communication Center (GCC).

\section{References}

[1] A. Tiwana, Knowledge Management Toolkit: Orchestrating IT, Strategy, and Knowledge Platforms. Upper Saddle: Prentice Hall, 2002.

[2] D. E. McNabb, Knowledge Management in the Public Sector: A Blueprint for Innovation in Government. New York: M. E. Sharpe. 2007.

[3] F. Inoue, "As a Language of Science in Japan. From Corpus Planning to Status Planning", in The Dominance of English as a Language of Science: Effects on Other Languages and Language Communities, U. Ammon, Ed. Mouton de Gruyter: Berlin, 2001, pp. 447-469.

[4] Gendai Haiku. gendaihaiku.com, (Access date: 2 Dec. 2012).

[5]Global30.http://www.uni.international.mext.go.jp/globa 130/( 25 June \& 25 Nov 2012)

[6] I. Nonaka, and H. Takeuchi, The Knowledge-Creating Company. Oxford: New York, 1995.

[7] JAIST, Japan Advanced Institute of Science and Technology, JAIST, Institute of General Education. http://www.jaist.ac.jp/english/research/general_education.h tml, (Access date: 5 June 2012).

[8] JAIST, Japan Advanced Institute of Science and Technology Prospectus, Public Relations and Coordination Department, Japan: Asahidai, 1990, 1996, 2000, 20002001, 2004, 2007, 2008, 2009 and 2010.

[9] JAIST, Japan Advanced Institute of Science and Technology website http://www.jaist.ac.jp.(Access date: 5 November 2010 \& 25 June 2012).

[10] N. R Gottlieb. and P. Chen, "Language planning and language policy in East Asia: An overview", in Language Planning and Language Policy: East Asian Perspectives, N.R. Gottlieb and P. Chen, Ed. Surrey, UK: Curzon Press, 2001, pp.1-20.

[11] P. Drucker, Post-Capitalist Society. New York: HarperBusiness, 1993.

[12] R.B. Kaplan, "The Hegemony of English in Science and Technology," Journal of Multilingual and Multicultural Development, vol.14, nos. 1 \& 2, 1993, pp.151-172.

[13] TOEIC. http://www.toeic.or.jp/toeic_en/. (Access date: 2 December 2012). 
[14] U. Ammon and G. McConnell, English as an Academic Language in Europe, Germany: Peter Lang, 2002.

[15] W. Grabe and R.B. Kaplan, "Science, Technology, Language, and Information: Implications for language and language-in-education planning," International Journal of the Sociology of Language, 59, 1986, pp.47-71.

[16] Z. Zaaba, I.N.A.Aning, H. Gunggut, F. I. M. Ramadan and K. Umemoto, "English as a Medium of Instruction in the Public Higher Education Institution: A Case Study of Language-in-Education Policy in Malaysia", in Selected Topics in Education and Education Technology, H. Fujita and J. Sasaki, Ed. Iwate, Japan: WSEA, 2010, PP 188-196.

[17] Z. Zaaba, F.I. Ramadan, I.N.A. Aning, H. Gunggut, and K. Umemoto, "Language-in-Education Policy: A Study of Policy Adjustment Strategy in Malaysia," International Journal of Education and Information Technologies, 2(5), 2011, pp.156-173.

[18] Zaaba, Z., Ramadan, F. I. M., Gunggut, H., Chuah Bee Leng, and Umemoto, K., "Internationalization of Higher Education: A Case Study of Policy Adjustment Strategy in Malaysia", International Journal for CrossDisciplinary Subjects in Education (IJCDSE), Special Issue 1(1), 2011, pp.565-576. 